\title{
Visual Discrimination and Reading for Children Dyslexic Arabophone, Aged 7.5 - 11.5 Years
}

\author{
Ahlam El Moutez, Mostapha El Alaoui Faris, Maria Benabdejlil \\ Department of Neurology and Neuropsychology A, Faculty of Medicine and Pharmacy, Rabat, Mohammed 5 University, \\ Rabat, Morocco \\ Email: mustapha.elalaouifaris@gmail.com,benab.maria@yahoo.fr
}

How to cite this paper: El Moutez, A., El Alaoui Faris, M., \& Benabdejlil, M. (2018). Visual Discrimination and Reading for Children Dyslexic Arabophone, Aged 7.5 11.5 Years. Psychology, 9, 2159-2174.

https://doi.org/10.4236/psych.2018.98123

Received: June 11, 2018

Accepted: August 13, 2018

Published: August 16, 2018

Copyright $\odot 2018$ by authors and Scientific Research Publishing Inc. This work is licensed under the Creative Commons Attribution International License (CC BY 4.0).

http://creativecommons.org/licenses/by/4.0/

\begin{abstract}
Objective: The objective of this study is to evaluate visual discrimination in an Arabic-speaking environment and then to appreciate the contribution of its disorders in the treatment of the Arabic language written for the Arabic-speaking reader. Method: A visual discrimination measuring instrument was created and adapted based on the test of the letter sequence discrimination of the battery. The structure of the Arabic language has been taken into consideration in the design of the items (vocalization). This test was applied to an individual based on different types of children from different age groups and different types of schools in Rabat, capital of Morocco. The standard methodology for the administration of created tests has been respected. Standard statistical indices were applied to analyze the measurement results and discuss the different possible interactions. Psychometric indices, as reliability, validity and correlation indices, were applied to assess the performance of the created test. Results and conclusion: The test used, was designed, adapted and standardized to the Arabic-speaking population of Moroccan children. The results obtained were summarized in the following points: 1) The standards obtained could be applied by health professionals to assess the performance of visual discrimination in relation to reading. 2) The main factors of segregation of children (gender and type of school) have no influence on visual discrimination. 3) Vocalization slows down reading for normal readers. On the other hand, it stimulates the attention in the dyslexics. 4) The visual discrimination disorder is present in dyslexic children at $69 \%$ (two out of three children).
\end{abstract}

\section{Keywords}

Visual Discrimination, Reading and Vocalization, Learning Disabilities, Assessment, Arabic Language, Dyslexia, Children, Norms 


\section{Introduction}

The aim of this work is to evaluate visual discrimination in an Arabic-speaking environment and then to appreciate the contribution of its disorders in the treatment of the Arabic language written by the Arabic-speaking child reader. To achieve this goal, we have been forced to develop a visual discrimination measurement instrument adapted to the Arabic-speaking environment. This instrument construction is a requirement. This construction and standardization of measuring instrument is required for this study, and important for professionals facing an Arabic-speaking population.

We mention three issues that have motivated this study:

\section{- Study of the magnocellular hypothesis}

Examination of the magnocellular hypothesis in an Arabic-speaking context is the main motivation for this study.

The vision is the main function of perception of images, colors, shapes and words etc. This function develops very early in the human. The child uses it from its first weeks of life to explore its environment. For this, he performs saccades, vergences and eye fixations, multiple and in all directions. An appropriate oculomotor control is essential for the proper functioning of the vision. Indeed, ocular saccades are very fast movements of both eyes, in the same direction and with the same amplitude. Vergence is the movement of the eyes, from distant objects to near objects and vice versa. On the other hand, visual fixation allows the subject to identify an object by observing its particular characteristics. For some researchers, reading is based first of all on the quality of vision, which is considered as a driving act (Kapoula, Bucci, Jurion, Ayoun, \& Afkhami, 2006). Indeed, during reading, the central nervous system exerts motor control of the gaze in three dimensions, horizontally, vertically and in depth, for both eyes simultaneously.

In 1985, John Stein et al. put forward the idea that dyslexics suffer from binocular instability associated with problems of convergence and ocular saccadic planning, which would cause difficulties in the perception of words or ocular displacement within a text with visual fatigability (Stein \& Fowler, 1985; Eden, Stein, Wood, \& Wood, 1994).

Moreover, the studies of Tiadi et al. in 2014 showed that dyslexic children have a significantly longer latency during binocular movements, a mean speed compared to non dyslexic children (Tiadi, Seassau, Bui-Quoc, Gerard, \& Bucci, 2014).

According to Tiadi's work in 2016, disorders of the treatment of written language (dyslexia) are characterized by oculomotor disturbances that are explained by the atypical development of the magnocellular visual system (Tiadi, 2016).

The magnocellular system is specialized in the treatment of monochromatic contrasts (Vital-Durand, 1985). In fact, two distinct pathways carry visual information from the retina to the cortex: the ventral pathway consists of magnocellular neurons and the dorsal pathway consists of parvocellular neurons. The first path is concerned with brief stimuli and the second with static stimuli (Page, 
King, Merigan, \& Maunsell, 1994).

Several researchers suggest that dyslexics have abnormalities in the magnocellular system. Indeed, contrast sensitivity functions are different between normo-readers and dyslexics and the results are discussed in terms of underlying mechanisms (Martin \& Lovegrove, 1984).

\section{- The peculiarity of the structure of the Arabic language}

The main language of Morocco is Arabic dialect, spoken and understood by all, except for some enclave Berber-speaking regions, whose populations remain unilingual.

Even if it is the mother tongue of the children: the entry into the writing and all the learning takes are in standard Arabic, a language which is not entirely foreign to the children who enter the language school but that requires them a real effort (Bourdereau, 2006).

The structure of the Arabic language is peculiar, because, on the one hand, the majority of letters consist of several elements that change morphologically during the connection, and differ only in the addition or deletion of an element (point or bar). On the other hand, the position at the top and bottom of the diacritics, or vocalization would change the meaning of the word. This would require, from the Arabic-speaking reader, a parallel and vigilant visual treatment, which would result in a more developed visual attention.

\section{- Lack of instrument for measuring visual discrimination}

As part of the assessment of reading the Arabic language, health professionals in Morocco are not equipped to measure the treatment of visual discrimination. This study would at least provide professionals with an adapted and standardized measuring instrument for the population of Arabic-speaking children.

Moreover, this context has an instrument for evaluating the written Arabic language processing based essentially on the measurement of the reading of words and texts in Arabic. It allows appreciating with precision the existence or not of a disorder of treatment of the written language (El Moutez et al., 2018). However, it is not enough to highlight the relationship of this disorder with another dysfunction, in this case, the disorder of visual discrimination.

This work consisted, initially, to the construction of an instrument, designated M3, measuring oculomotor skills specific to the population of Arabic speaking children. This test was developed by following the steps of the process of constructing a psychometric test (Grégoire, Jacques, \& Laveault, 2014). The performance of the M3 test was confirmed by the quality of the statistical indices of reliability, validity and standardization. This led to the establishment of centile standards and critical thresholds of the subtests.

Second, we applied the M3 test to a sample of dyslexic children, to evaluate visual discrimination. The dyslexia of these children is confirmed by the P1 test and speech therapists. Subsequently, we examined the degree of presence of visual disorders in these children.

Finally, we discussed: 1) the administration to dyslexics children, 2) Depen- 
dence of language processing and visual discrimination, 3) the impact of vocalization as a peculiarity of language in both types of population, 4) the particular cases of dyslexic profiles from the links observed.

\section{Methods}

\section{1) Materiel of the Recognition Words Written test P1}

The P1 test was developed, adapted and validated by A.ELMOUTEZ in the Arabic-speaking context to evaluate the written language treatment in Arabic (El Moutez et al., 2018). Its detailed measurements make it possible to identify the dyslexic children of normal readers and to specify the performance of the different reading paths (addressing or assembly). The material (items) of this test was designed taking into account the peculiarities of the structure of the Arabic language (morphology and diacritics). This justified the choice of its use.

It consists of three lists of words, each based on a separate property relating to the Arabic language. (P11 word vocalized, P12: not vocalized words and P13 nickname vocalized words).

\section{2) Materiel of the visual discrimination test M3}

The M3 test was created to evaluate oculomotor skills, based on the visual treatment of Arabic letter sequences, inspired from the test of the discrimination of the sequences of letters of the Odédys battery (Jacquier-Roux, Monique, Valdois, Sylviane, \& Zorman, 2002). M3 is composed of two dozen pairs of isolated and meaningless consonant sequences. The first list of M31 contains unvocalised letters (Table 1, List 1). Given the importance of vocalization as a feature of the Arabic language, the sequences in the second M32 list are vocalized (Table 1, List 2). The sequences are composed of 3 to 4 letters, sometimes attached. For each pair of sequences, the letters are generally near graphically. The letters of the two sequences to compare are different in themselves or they have different

Table 1. List of letter sequences of M3.

\begin{tabular}{|c|c|c|c|c|c|}
\hline \multicolumn{4}{|c|}{ M31: List 1} & \multicolumn{2}{|c|}{ M32: List 2} \\
\hline 1 & ب و ن ل & ب ون ل & 11 & حَبِكِ & حَسَكَكِ \\
\hline 2 & د س ف & س ف د & 12 & دَسنَ فُ & دَسِ فُ \\
\hline 3 & ب ن س ش & ن ب س ش & 13 & بَنَّنح & بَنَّنُحُ \\
\hline 4 & ج亡 & حج & 14 & حَخُ جَ & حَخْ جَ \\
\hline 5 & ف ث م ج & ف ث م ج & 15 & تُحْفِ & تُحْفِ \\
\hline 6 & ف ل ن ق & ف ل ن ق & 16 & قُ لْنَفْ & قُ لْنَفْ \\
\hline 7 & ح س ك & ج س ك & 17 & بَوَ نُ لُ & بََوَنُ لُُ \\
\hline 8 & ي ن ح & ى ن ح & 18 & فَفَثْنَج & فَفَتَنَج \\
\hline 9 & ت ح ف & ت ح ف & 19 & بَ نْ سَ شُ & بَ نْ سَ شُّ \\
\hline 10 & رز خ ف & رز حف & 20 & رَزَخَفُ & رَزْ خَخُُ \\
\hline
\end{tabular}


positions in the two sequences. The child must compare them two by two and judge if the two sequences are identical. The measurement of each sub-test (M31, M32) is the number of correctly compared sequences per minute. The measure of $\mathrm{M} 3$ is the average of the two subtests.

We emphasize that M3 evaluates, in the same reading conditions, visual processing which is one of the components of the reading process. Indeed, the word is a series of letters that make sense, and therefore treatment sequences is considered a prerequisite of reading, its dysfunction inevitably influence the reading.

3) Sample of Dislexic Children for Examination of Visual Discrimination

Several centers of speech therapy in the Rabat city have agreed to provide us cases of dyslexia. After parental consent, we applied the P1 test to these children in order to confirm the diagnosis of dyslexia, then the M3 test was applied to assess the quality of visual discrimination. All children proposed are confirmed dyslexic by the P1 test.

The sample consists of 16 children aged 7 to 12 years, boys and girls, from both private and public schools.

4) Sampling for the standardization of the M3 test

The research team obtained the approval of the Ministry of National Education to pass the test to schoolchildren. Indeed, the M3 test was applied individually to the sample by the author, with the assistance of the research team of the Faculty of Medicine of Rabat and school's pedagogical team. The application process lasted nearly six months.

\section{Participants.}

This study focuses on a population of Moroccan children, Arabic speaking, schooled and aged from 7 to 12 years. A random sample of 120 children was selected from schools in the Rabat city. The criteria for selection of the sample:

- The grade is from second to sixth grade of the primary school (CE2 to CE6).

- As many boys as girls per level grade.

- As many children in private schools than in public schools

- From different social backgrounds

\section{Exclusion criteria:}

- Without cognitive or psychic developmental disorders,

- Without psychological, psychomotor or speech therapy.

The sampling is based on the random selection of children, in each school by grade, according to the mentioned criteria.

Age is determined by the number of months at the time of assessment. We propose five age groups, with a 12-month step. This distribution is consistent with the school level of the children (Table 2).

5) Methodology for the standardization of the M3 test

The experimentation of the test M3 was carried out in several stages:

- Definition of the target population and selection of the sample (see below Table 2). 
Table 2. The characteristics of the sampling. (G: girl, B: boys, P: public, V: private).

\begin{tabular}{|c|c|c|c|c|c|c|c|c|c|c|c|c|c|}
\hline \multirow{2}{*}{ Age } & \multirow{2}{*}{$\begin{array}{c}\text { Number } \\
\text { Total }\end{array}$} & \multicolumn{2}{|c|}{ CE2 } & \multicolumn{2}{|c|}{ CE3 } & \multicolumn{2}{|c|}{ CE4 } & \multicolumn{2}{|c|}{ CE5 } & \multicolumn{2}{|c|}{ CE6 } & \multicolumn{2}{|c|}{ Total } \\
\hline & & G & B & G & B & G & B & G & B & G & B & $P$ & $\mathrm{~V}$ \\
\hline $71 / 2$ & 22 & 10 & 12 & & & & & & & & & 10 & 12 \\
\hline $8^{1 / 2}$ & 22 & 2 & & 10 & 10 & & & & & & & 13 & 9 \\
\hline $9^{1 / 2}$ & 26 & & & 2 & 2 & 12 & 10 & & & & & 13 & 13 \\
\hline $10^{1 / 2}$ & 22 & & & & & & 2 & 9 & 11 & & & 11 & 11 \\
\hline $11^{1 / 2}$ & 28 & & & & & & & 3 & 1 & 11 & 13 & 14 & 14 \\
\hline & 120 & 12 & 12 & 12 & 12 & 12 & 12 & 12 & 12 & 11 & 13 & 61 & 59 \\
\hline
\end{tabular}

- Drafting of material (Table 1):

- Choice of letter sequences and elaboration of instructions

○ Preparation of written materials for children and for examiners

- Organization of test administration with schools

- Pre-administration to validate instructions and materials:

- Effective administration for data collection.

- Re-test to confirm the validity of the test (36 children).

- Analysis of the performance of M3 test and determination of standards 6) Statistical analysis tools

- The critical threshold is determined by $Z$ score $(Z=-1)$.

- To appreciate the performance of the M3 test and its components, it's necessary to calculate and analyze some important statistical indices such as the smallest and highest measures, the average, the standard deviation of the scores,

- The performance of the psychometric properties of the test was analyzed by the application of reliability and validity methods: Alpha Cronbach coefficient, split half, internal correlation, and retest.

- The standards are determined for M3 from the centiles and for the subtests from the thresholds calculated from means by deducting a unit of standard deviation.

\section{Results and Analysis of M3}

In this part, we presented all the steps required to validate the M3 test, which has been demonstrated by the quality of the inferential statistical indices. Thus, the M3 test would serve effectively to examine the relationship between visual discrimination and processing disorder of written Arabic language. This will be analyzed in the discussion and application section.

\section{- Analysis of the measurements of the subtests (Score per minute)}

The measure of M3 (mean value of M31 and M32) increases from 13.2 to 22.0 depending on the age of the children (Table 3, Figure 1 and Figure 2). Its extended is 8.8 over 5 years. They are relatively dispersed and represent $24 \%$ of the average (from 21\% to 29\%).The measure of M31 increases from 15.7 to 26.7 


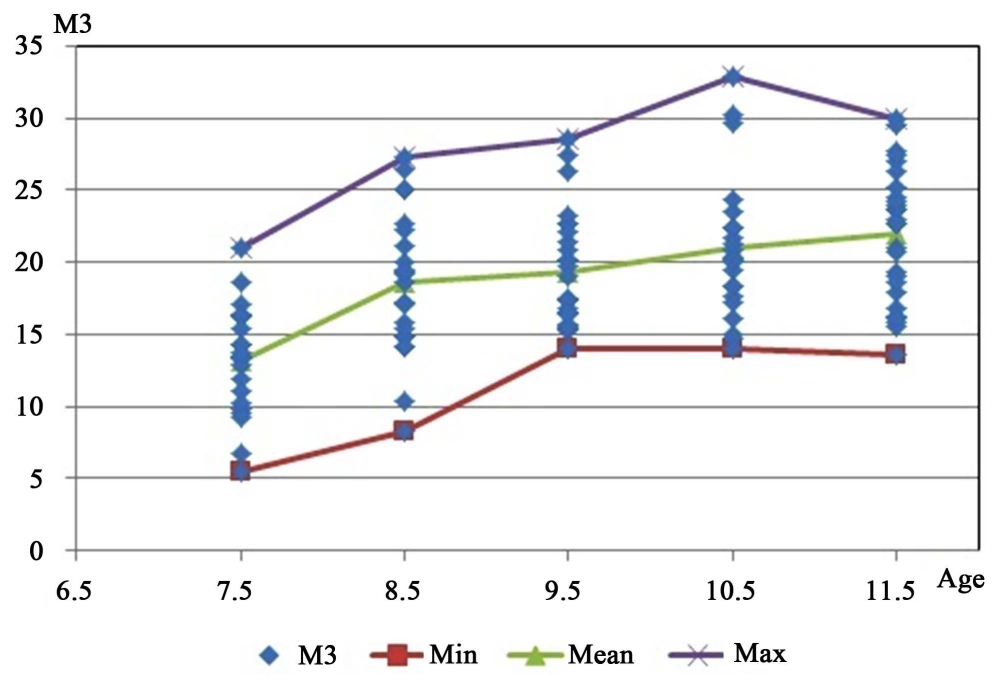

Figure 1. Cloud of measures of M3.

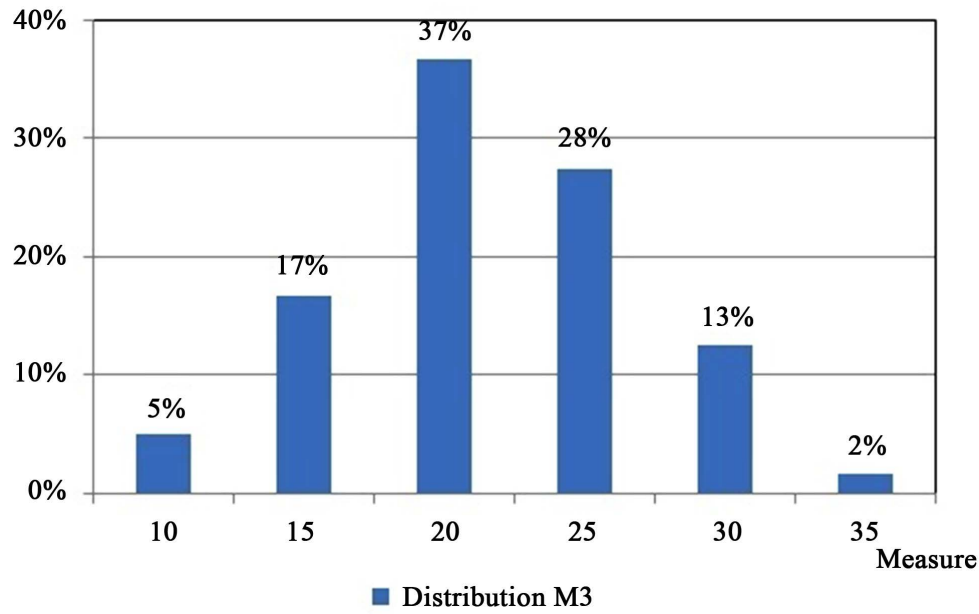

Figure 2. Distribution of measures of M3.

Table 3. Statistical indices of the test M3.

\begin{tabular}{|c|c|c|c|c|c|c|c|c|c|c|c|c|c|c|}
\hline \multicolumn{2}{|c|}{ Sample } & \multicolumn{5}{|c|}{ M3 } & \multicolumn{4}{|c|}{ M31: non vocalized } & \multicolumn{4}{|c|}{ M32: vocalized } \\
\hline Age & $\mathrm{Nb}$ & $\min$ & mean & $\max$ & SD & Cf.var & $\min$ & mean & $\max$ & SD & $\min$ & mean & $\max$ & SD \\
\hline $71 / 2$ & 22 & 5.4 & 13.2 & 21.1 & 3.8 & $29 \%$ & 4.9 & 15.7 & 23.1 & 5.0 & 4.7 & 10.7 & 20.7 & 3.9 \\
\hline $8^{1 / 2}$ & 22 & 8.7 & 18.6 & 27.2 & 5.0 & $27 \%$ & 7.3 & 22.7 & 35.3 & 7.0 & 8.4 & 14.4 & 22.9 & 4.0 \\
\hline $9^{1 / 2}$ & 26 & 14.0 & 19.4 & 28.5 & 4.0 & $21 \%$ & 13.5 & 23.0 & 40.0 & 6.1 & 10.0 & 15.8 & 30.0 & 4.0 \\
\hline $10^{1 / 2}$ & 22 & 14.0 & 20.9 & 32.9 & 5.0 & $24 \%$ & 15.0 & 25.4 & 37.5 & 6.3 & 8.4 & 16.4 & 28.4 & 5.3 \\
\hline $11^{1 / 2}$ & 28 & 13.5 & 22.0 & 29.9 & 4.5 & $21 \%$ & 13.8 & 26.7 & 35.3 & 6.3 & 8.8 & 17.3 & 25.7 & 4.6 \\
\hline Total & 120 & 5.4 & 19.0 & 33.0 & 5.3 & $28 \%$ & 4.9 & 22.9 & 40.0 & 7.0 & 4.7 & 15.1 & 30.0 & 4.9 \\
\hline
\end{tabular}

depending on the age of the children. For M32, it increases from 10.7 to 17.3. These measures are also dispersed and represent $31 \%$ of the M31 average and $32 \%$ of the M32 average. 
The treatment of non-vocalized sequences (M31) shows a higher performance than the vocalized sequences (M32).

\section{- Analysis of scores and treatment times}

M31 scores are constantly increasing and slightly from 8.9 to 9.7 out of 10 . M31 is therefore very accessible. The range is 0.8 points between $71 / 2$ years and $11 \frac{1 / 2}{2}$ years. It is noted that $97 \%$ of children had more than 7 points of which $58 \%$ answered all items.

The M32 score has risen steadily from 7.7 to 8.4 out of 10 . It is slightly lower than that of M31. Its range is 0.7 . The M31 test is slightly more accessible than the M32 test.76\% of children had more than 7 points, of which $20 \%$ answered all items (Figure 3).

Time decreases from $37.2 \mathrm{~s}$ to $23.0 \mathrm{~s}$ depending on the age of the children for M31 and from 46.4 to $30.8 \mathrm{~s}$ for M32. The range is 14.2 (M31), and 15.6 (M32). Both stretches are very close and small and so the performance is almost the same for all ages.

The time taken to answer an item is 2.90 seconds for non-vocalized sequences against 4.32 seconds for the vocalized sequences.

The improvement in treatment time is consistent with changes in age and decreases from 4.19 to $2.37 \mathrm{~s}$ (M31) and from 6.04 to $3.65 \mathrm{~s}$ (M32) (Table 4).

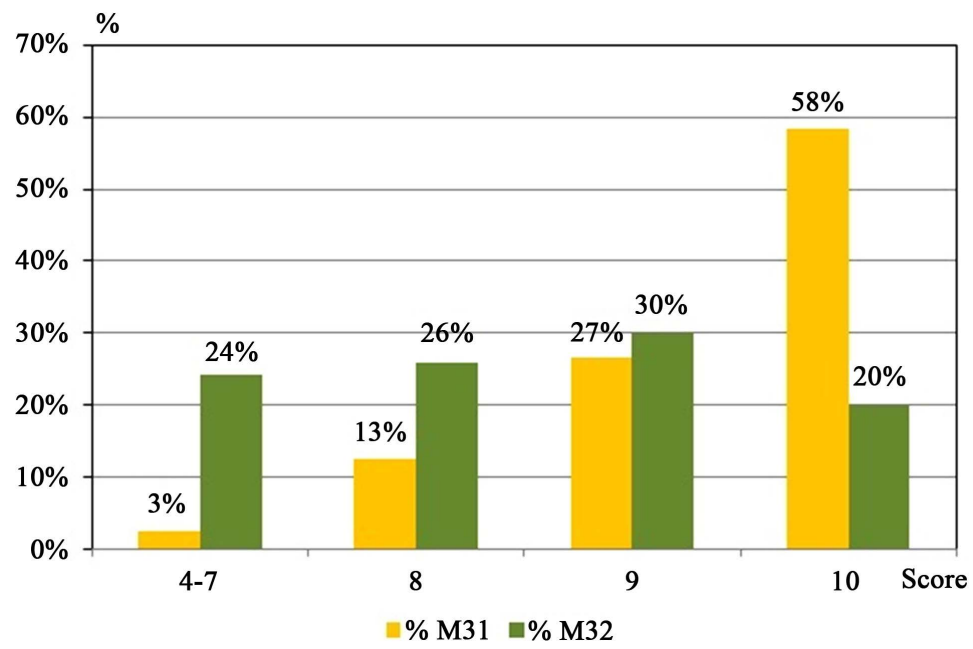

Figure 3. Distribution of M31 and M32 (scores).

Table 4. Scores and times of M31 and M32.

\begin{tabular}{ccccccc}
\hline Age & S31 & T31 & T31/s & S32 & T32 & T32/s \\
\hline $7^{1 / 2}$ & $\mathbf{8 . 9}$ & 37.2 & 4.19 & 7.7 & 46.4 & 6.04 \\
$81 / 2$ & 9.1 & 27.1 & 2.98 & 8.2 & 36.0 & 4.40 \\
$91 / 2$ & 9.5 & 26.1 & 2.76 & 8.6 & 34.3 & 3.98 \\
$101 / 2$ & 9.7 & 24.2 & 2.49 & 8.7 & 34.5 & 3.96 \\
$11^{1 / 2}$ & 9.7 & 23.0 & 2.37 & $\mathbf{8 . 4}$ & 30.8 & 3.65 \\
Total & 9.4 & $\mathbf{2 7 . 2}$ & $\mathbf{2 . 9 0}$ & $\mathbf{8 . 3}$ & 36.0 & 4.32 \\
\hline
\end{tabular}




\section{- Analysis of items}

The analysis of the responses by item in Table 5 shows that the 20 items are accessible and present an almost similar difficulty. It varies for M31, between $86 \%$ success for item 7 and $98 \%$ for item 9 , for M32 between $61 \%$ for item 20 and $99 \%$ for item 19 .

These high performances are in line with the profiles of the children in the sample, who are supposed to be normal readers and have no learning difficulties. The skill of visual discrimination should be well acquired.

On the other hand, it would argue that the two subtests would not allow for a clear classification of children, but meet our original goal of reading treatment diagnosis by defining the threshold of visual discrimination required.

- Analysis of the impact of the two factors: gender and type of school

The graphic presentation of the test M3 corresponding to homogeneous sub-populations: Girl, Boy, Public School, Private School confirms its regularity, its growth by age and provides information on the level of performance of each (Figure 4). We note that the growth is maintained in increments for gender and types of school, and the gender performance (of school types) is almost similar.

\section{- Reliability indices}

The alpha coefficient of Cronbach: The elements of each construct (M31 and

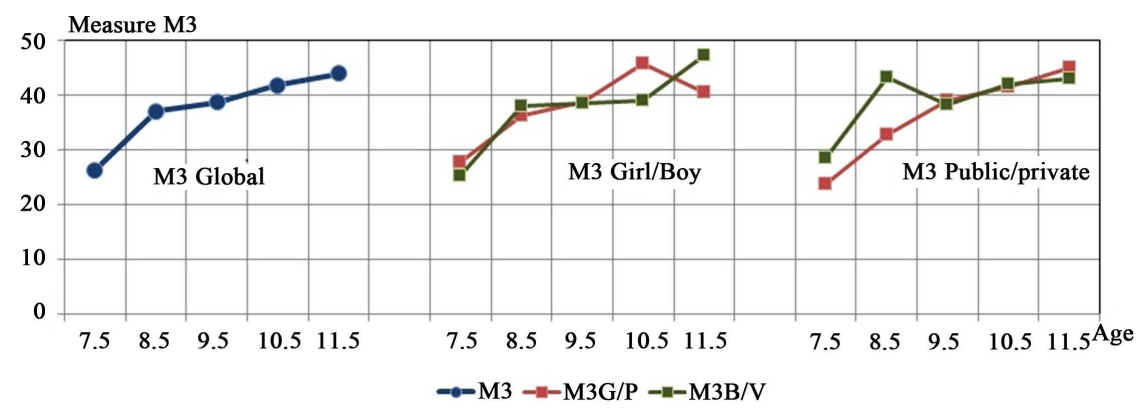

Figure 4. The measures of M3 by gender and by type of school according to the age.

Table 5. Difficulty of the items of M31 and M32.

\begin{tabular}{cccccc}
\hline item & M31 & $\%$ & item & M32 & $\%$ \\
\hline 1 & 108 & $90 \%$ & 11 & 94 & $78 \%$ \\
2 & 116 & $97 \%$ & 12 & 115 & $96 \%$ \\
3 & 114 & $95 \%$ & 13 & 107 & $89 \%$ \\
4 & 115 & $96 \%$ & 14 & 104 & $87 \%$ \\
5 & 115 & $96 \%$ & 15 & 83 & $69 \%$ \\
6 & 114 & $95 \%$ & 16 & 105 & $88 \%$ \\
7 & 103 & $86 \%$ & 17 & 85 & $71 \%$ \\
8 & 113 & $94 \%$ & 18 & 116 & $97 \%$ \\
9 & 118 & $98 \%$ & 19 & 119 & $99 \%$ \\
10 & 110 & $92 \%$ & 20 & 73 & $61 \%$ \\
\hline
\end{tabular}


M32) considered are the 10 items of each. The Cronbach Alpha coefficients calculated for each age group of children separately are all higher than 0.7 , so very satisfactory.

The split-half method: The same elements considered above are used in the bisection method. Reliability Coefficients are calculated by age group. We analyzed each sub-test (M31 and M32) separately, from a statistical point of view are very satisfactory. The Spearman-Brown and Guttman coefficients are significant and range from 0.698 to 0.973 .

\section{- Validity indices}

The graphic presentation of the retest according to the initial test shows that the majority of the points are around the first bisector and that they are linear. The corresponding correlation coefficients are $r(M 31)=0.68$ and $r(M 32)=0.58$. From this point of view, validity based on retest is also acceptable.

\section{- Norms of M3}

The gender and type of school factors no influence on the measures, so they were not considered in this calculation. The centiles are determined for M3 $(=(\mathrm{M} 31+\mathrm{M} 32) / 2)$ and shown by Table 8 .

Critical thresholds of the sub-tests M31 and M32 are determined by deduction one unite of the standard deviation (Table 9).

The calculation of the $z$-score makes it possible to appreciate its distance from the mean of the measurements in terms of standard deviation. This transformation provides information on the extent of its performance or difficulty.

\section{Discussion: Contribution of Visual Discrimination in the Disorder of the Treatment of Written Arabic Language}

The instrument M3 for measuring the quality of the visual discrimination of letter sequences has been validated, according to the satisfactory statistical indices of reliability (Table 6 and Table 7) and validity (Figure 5 and Figure 6). It has been standardized for the population of Moroccan children from 7.5 to 11.5. The norms, centiles for M3 (Table 8) and thresholds for M31 and M32 (Table 9) obtained by age are determined independently of the gender and type of school factors, and can be generalized to the population of Moroccan children.

Thus health professionals would be equipped with an effective instrument for assessing visual discrimination.

To answer the objective of the study, we propose to discuss 3 applications.

Table 6. Cronbach Alpha coefficients of M31, M32 (SPSS source).

\begin{tabular}{ccc}
\hline Age & M31 & M32 \\
\hline $7^{1 / 2}$ & 0.92 & 0.74 \\
$8^{1 / 2}$ & 0.91 & 0.77 \\
$9^{1 / 2}$ & 0.92 & 0.76 \\
$10^{1 / 2}$ & 0.95 & 0.85 \\
$11^{1 / 2}$ & 0.96 & 0.83 \\
\hline
\end{tabular}




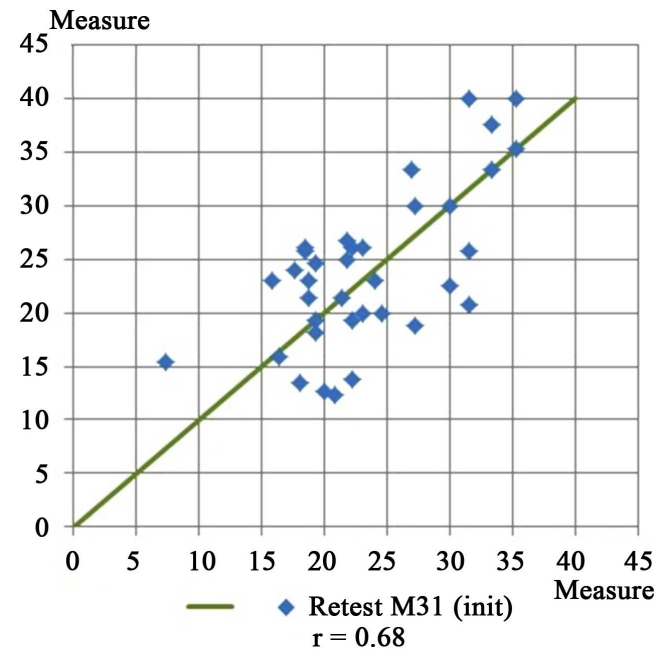

Figure 5. Point cloud of the M31 retest vs initial test.

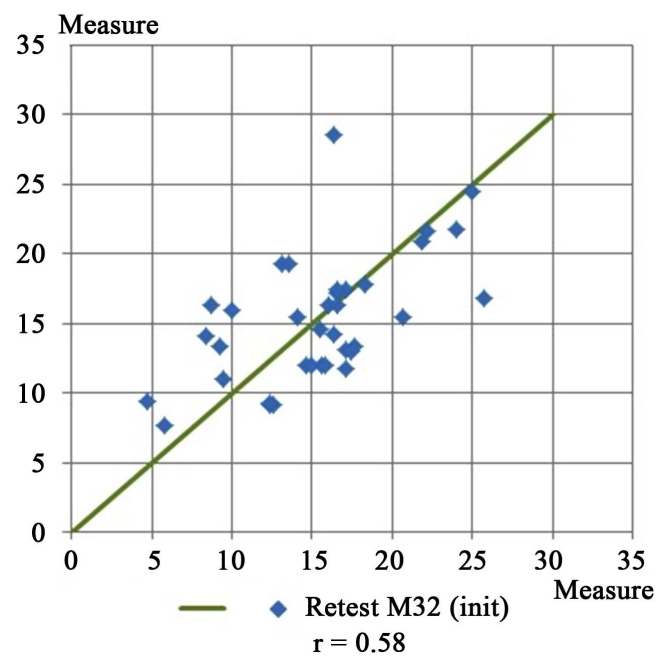

Figure 6. Point cloud of the M32 retest vs initial test.

Table 7. The coefficients of the split half method of sub-tests M31 and M32 by age group (SPSS source).

\begin{tabular}{|c|c|c|c|c|c|c|c|c|c|c|c|c|}
\hline \multirow{2}{*}{\multicolumn{3}{|c|}{$\begin{array}{c}\text { Reliability statistics } \\
\text { of M31 and M32 }\end{array}$}} & \multicolumn{5}{|c|}{ M31 } & \multicolumn{5}{|c|}{ M32 } \\
\hline & & & $71 / 2$ & $81 / 2$ & $91 / 2$ & $101 / 2$ & $11 \frac{1}{2}$ & $71 / 2$ & $81 / 2$ & $91 / 2$ & $101 / 2$ & $11 \frac{1 / 2}{2}$ \\
\hline \multirow{2}{*}{\multicolumn{2}{|c|}{ Partie 1}} & Value & 0.846 & 0.962 & 0.777 & 0.882 & 0.896 & 0.076 & 0.415 & 0.665 & 0.583 & 0.762 \\
\hline & & $\mathrm{Nb}$ elem & $5^{\mathrm{a}}$ & $5^{\mathrm{a}}$ & $5^{\mathrm{a}}$ & $5^{\mathrm{a}}$ & $5^{\mathrm{a}}$ & $5^{\mathrm{a}}$ & $5^{\mathrm{a}}$ & $5^{\mathrm{a}}$ & $5^{\mathrm{a}}$ & $5^{\mathrm{a}}$ \\
\hline \multirow[t]{3}{*}{ Alpha } & \multirow{2}{*}{ Partie 2} & Value & 0.828 & 0.734 & 0.908 & 0.918 & 0.946 & 0.743 & 0.767 & 0.538 & 0.785 & 0.764 \\
\hline & & $\mathrm{Nb}$ elem & $5^{b}$ & $5^{b}$ & $5^{\mathrm{b}}$ & $5^{\mathrm{b}}$ & $5^{\mathrm{b}}$ & $5^{\mathrm{b}}$ & $5^{\mathrm{b}}$ & $5^{\mathrm{b}}$ & $5^{\mathrm{b}}$ & $5^{\mathrm{b}}$ \\
\hline & \multicolumn{2}{|c|}{ Nb total d'éléments } & 10 & 10 & 10 & 10 & 10 & 10 & 10 & 10 & 10 & 10 \\
\hline \multicolumn{3}{|c|}{ Correlation between subscales } & 0.894 & .757 & 0.924 & 0.947 & 0.895 & 0.766 & 0.648 & 0.640 & 0.915 & 0.539 \\
\hline \multirow{2}{*}{\multicolumn{2}{|c|}{$\begin{array}{l}\text { Coeff. } \\
\text { Spearman-Brown }\end{array}$}} & Equal length & 0.944 & 0.862 & 0.960 & 0.973 & 0.944 & 0.868 & 0.787 & 0.781 & 0.956 & 0.700 \\
\hline & & Unequal length & 0.944 & 0.862 & 0.960 & 0.973 & 0.944 & 0.868 & 0.787 & 0.781 & 0.956 & 0.700 \\
\hline \multicolumn{3}{|c|}{ Coeff. Guttman split-half } & 0.940 & 0.862 & 0.960 & 0.972 & 0.944 & 0.837 & 0.774 & 0.778 & 0.951 & 0.698 \\
\hline
\end{tabular}


Table 8. Centiles ranks of M3.

\begin{tabular}{cccccccc}
\hline \multicolumn{7}{c}{ Centiles M3 } \\
\hline Age & $\mathbf{5 6}$ & $\mathbf{1 0}$ & $\mathbf{2 5}$ & $\mathbf{5 0}$ & $\mathbf{7 5}$ & $\mathbf{9 0}$ & $\mathbf{9 5}$ \\
\hline $71 / 2$ & 5.6 & 7.5 & 10.1 & 13.4 & 16.2 & 18.2 & 20.7 \\
$81 / 2$ & 8.6 & 11.4 & 14.9 & 18.9 & 22.3 & 26.0 & 27.1 \\
$91 / 2$ & 14.5 & 15.3 & 16.2 & 18.3 & 22.2 & 26.7 & 28.2 \\
$10^{1 / 2}$ & 14.1 & 14.8 & 17.5 & 20.2 & 22.7 & 30.0 & 32.5 \\
$11 \frac{1}{1 / 2}$ & 14.4 & 15.7 & 18.1 & 22.8 & 25.1 & 28.0 & 29.7 \\
\hline
\end{tabular}

Table 9. Critical thresholds of the M31 and M32.

\begin{tabular}{ccc}
\hline Age & M31 & M32 \\
\hline $71 / 2$ & 10.6 & 6.8 \\
$8^{1 / 2}$ & 15.7 & 10.4 \\
$91 / 2$ & 16.8 & 11.7 \\
$10^{1 / 2}$ & 19.2 & 11.1 \\
$11^{1 / 2}$ & 20.4 & 12.7 \\
Total & 15.8 & 10.2 \\
\hline
\end{tabular}

\section{- Application 1: Administration to dyslexics}

The M3 test was applied to a population of 16 dyslexic children who are confirmed by speech therapists and the P1 test (the $\mathrm{z}$ of the three sub-tests P11, P12 and P13 is less than -1 ). The results of M3 show that the visual discrimination disorder is present in dyslexics (the average $\mathrm{z}$ score of M31 and M32 is less than -1) (Table 10). We recorded more than two out of three dyslexic children exhibit visual discrimination deficit.

Also, we find that the mean $\mathrm{Z}$ of M32 (=-1.14) is greater than that of M31 $(-1.50)$, which would result in a degradation of the visual discrimination of the non-vocalized sequences compared to the vocalized ones in the dyslexic. This paradoxical phenomenon can be explained by the fact that vocalization generates an attentional effort that favors comparison.

We note that $14 / 16$ or $84 \%$ of children are affected by at least one sub-test (14 $=7+4+3$, Table 11).

\section{- Application 2: Dependence of language processing and visual discrimination}

The calculation of the correlation coefficients between the visual discrimination M31, M32 and those of the reading, P11, P12 and P13, would make it possible to assess the extent of dependence of these two skills on a normal population. Table 12 clearly shows that there is an average dependence in the neighborhood of 0.5 and that it is kept stable between all the sub-tests of the reading and those of the visual discrimination. 
Table 10. Statistical indices of $\mathrm{z}$ score of visual discrimination for dyslexics.

\begin{tabular}{cccccc}
\hline Test & Deficit & $\mathrm{Z}$ min & $\mathrm{Z}$ mean & $\mathrm{Z}$ max & $\mathrm{Z}$ st \\
\hline M31 & $11 / 16,69 \%$ & -2.56 & -1.50 & 0.11 & 0.90 \\
M32 & $10 / 16,63 \%$ & -2.23 & -1.14 & 1.57 & 0.95 \\
\hline
\end{tabular}

Table 11. Distribution of dyslexics in relation to the deficit of the M31 and M32.

\begin{tabular}{ccccc}
\hline & \multicolumn{4}{c}{ Dyslexic } \\
\cline { 2 - 4 } M31/M32 & $-/-$ & $-/+$ & $+/-$ & $+/+$ \\
\hline Number, $\%$ & $7 / 16,43 \%$ & $4 / 16,25 \%$ & $3 / 16,19 \%$ & $2 / 16,13 \%$ \\
\hline
\end{tabular}

Table 12. Correlation coefficients of the M3 and P1 tests.

\begin{tabular}{ccccccc}
\hline & P11 & P12 & P13 & P1 & M31 & M32 \\
\hline M31 & 0.49 & 0.48 & 0.48 & 0.51 & 1 & 0.56 \\
M32 & 0.55 & 0.54 & 0.54 & 0.57 & 0.56 & 1 \\
& & & Dyslexics & & & \\
M31 & 0.43 & 0.33 & 0.31 & 0.39 & 1 & 0.55 \\
M32 & 0.56 & 0.43 & 0.63 & 0.58 & 0.55 & 1 \\
\hline
\end{tabular}

For dyslexics, we find that the sub tests of $\mathrm{P} 1$ and $\mathrm{M} 3$, using the vocalization, show an improvement in the correlation coefficients. While non-vocalized sub-tests show more independence. This suggested an additional attentional contribution generated by vocalization.

Figure 7 shows the performances in reading and visual processing in the form of a scatter plot for the two types of populations, normo-reader and dyslexic. The $\mathrm{x}$-axis represents the $\mathrm{z}$-score of $\mathrm{P} 1$ and the $\mathrm{y}$-axis represents the $\mathrm{z}$-score of M31 or M32. This presentation shows the disposition of the two populations and clearly shows the impact of visual discrimination in dyslexics, and that of vocalization.

\section{- Application 3: Impact of the vocalization}

For the normal reader, the impact of vocalization on visual processing can be appreciated by the relative difference between the scores of the two sub-tests and the two measures. Table 13 shows that this difference is relatively stable compared to age, namely $11 \%$ for the scores only and $34 \%$ for the measures (including the time).

Thus we can say that the shift of $34 \%$ provides information on two cumulative impacts, the decoding of diacritics and the response time (responsiveness). It is composed of $11 \%$ due to the decoding of diacritics and $23 \%$ of the additional time allocated to the decoding of diacritics. 

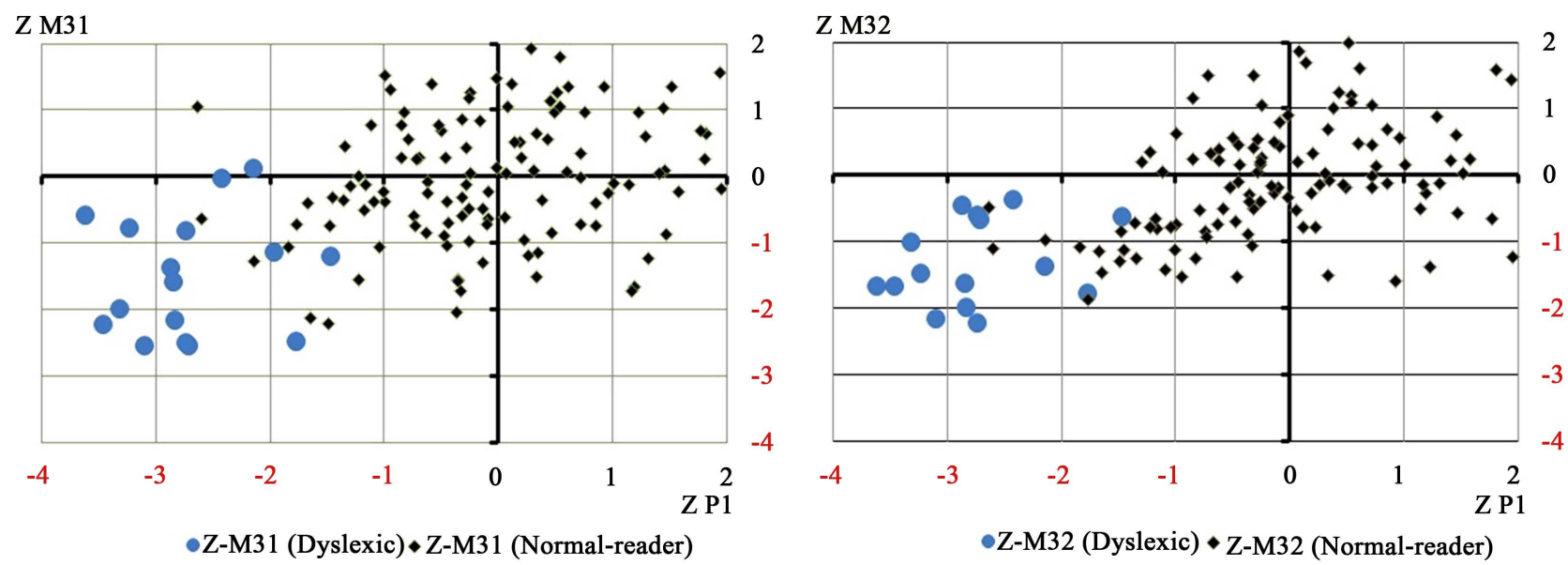

Figure 7. Cloud of Z score (P1, M31 or M32).

Table 13. Vocalization Impact of normal reader.

\begin{tabular}{cccccccc}
\hline Age & $\mathrm{m} 31$ & $\mathrm{~m} 32$ & gap & $\mathrm{s} 31$ & $\mathrm{~s} 32$ & gap & dif \\
\hline $71 \frac{1}{2}$ & 15.7 & 10.7 & $32 \%$ & 8.9 & 7.7 & $13 \%$ & $18 \%$ \\
$81 \frac{1}{1 / 2}$ & 22.7 & 14.4 & $37 \%$ & 9.1 & 8.2 & $10 \%$ & $27 \%$ \\
$91 / 2$ & 23.0 & 15.8 & $31 \%$ & 9.5 & 8.6 & $9 \%$ & $22 \%$ \\
$10^{1 / 2}$ & 25.4 & 16.4 & $35 \%$ & 9.7 & 8.7 & $10 \%$ & $25 \%$ \\
$11^{1 / 2}$ & 26.7 & 17.3 & $35 \%$ & 9.7 & 8.4 & $13 \%$ & $23 \%$ \\
Total-NR & 22.9 & 15.1 & $34 \%$ & 9.4 & 8.3 & $11 \%$ & $23 \%$ \\
Total-DC & 13.02 & $\mathbf{9 . 8 1}$ & $\mathbf{2 5 \%}$ & $\mathbf{8 . 2 5}$ & $\mathbf{7 . 1 9}$ & $\mathbf{1 3 \%}$ & $\mathbf{1 2 \%}$ \\
\hline
\end{tabular}

NR: normal reader, DC: dyslexic children.

Thus, vocalization is a factor slowing down the process of visual processing of letter sequences for children normo-readers.

For dyslexic children, the results are reversed. The difference in the measurements decreases from $34 \%$ to $25 \%$ while that of the scores goes from $11 \%$ to $13 \%$. This means that vocalization generates an extra attention. This is consistent with the results obtained above.

Thus, it is recommended, when screening for dyslexia, first to check the quality of the child's visual discrimination. And in the case of a visual processing disorder, place an oculomotor reeducation with emphasis on the vocal sequences before placing the speech therapy.

- Application 4: The particular cases of dyslexic profiles from the links observed

Finally we present in Figure 8, the 4 possible dyslexic cases encountered in our population of dyslexics and the particular case of normo-reader with a visual discrimination disorder. 


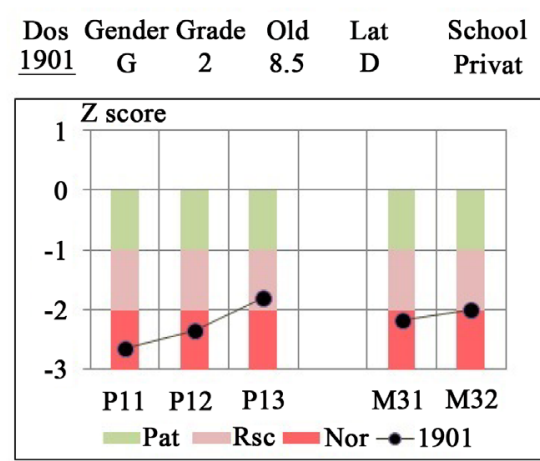

Both reading and visual processing performance is impaired (43\%). In this case, the reading disability is related to visual skills.

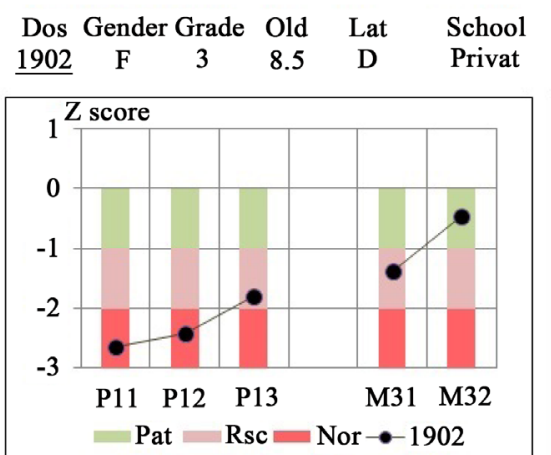

Reading performance is impaired and performance of visual processing is impaired especially for non-vocalized sequences (25\%).

The reading disability would not necessarily be related to visual processing because the M32 is not affected.
Dos Gender Grade Old Lat School $\begin{array}{llllll}1903 & G & 4 & 9.5 & D & \text { Privat }\end{array}$

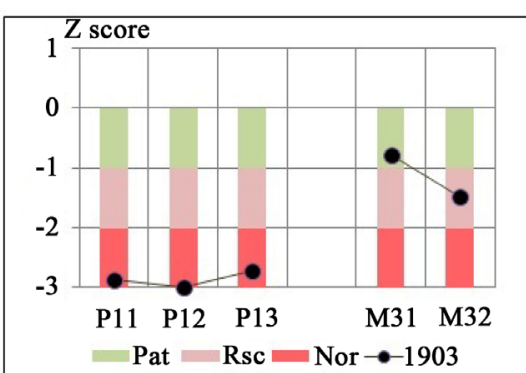

Reading performance is very impaired and the visual processing is impaired especially for the vocalised sequences $(19 \%)$. Reading disability would not necessarily be related to visual skills

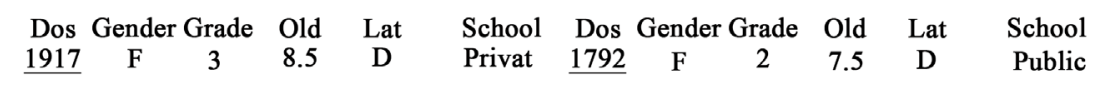

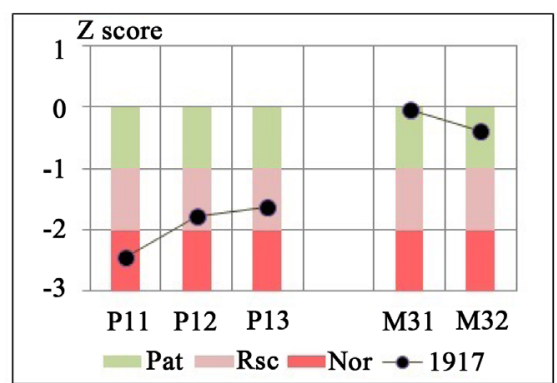

The reading performance is impaired and the visual processing is preserved. The reading disability is marked and it would not, in any case, be related to visual processing (13\%).

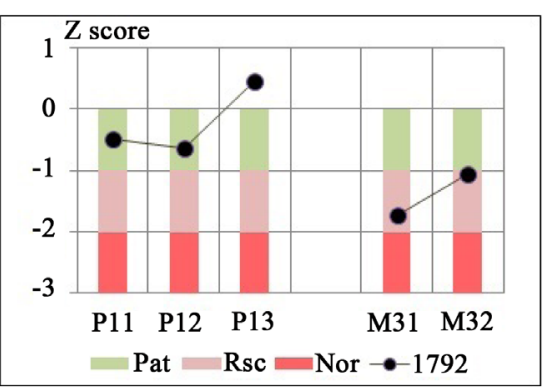

The reading performance is preserved. The visual processing performance is impaired.

Visual processing does not affect reading.

Figure 8. Possible case of reading association with visual processing.

\section{Conflicts of Interest}

The authors declare no conflicts of interest regarding the publication of this paper.

\section{References}

Bourdereau, F. (2006). Le français aujourd'hui, 154, 25-34. https://doi.org/10.3917/lfa.154.0025

Eden, G. F., Stein, J. F., Wood, H. M., \& Wood, F. B. (1994). Differences in Eye Movements and Reading Problems in Dyslexic and Normal Children. Vision Research, 34, 1345-1358. https://doi.org/10.1016/0042-6989(94)90209-7

El Moutez, A., El Alaoui Faris, M., \& Benabdejlil, M. (2018). Normative Study of the Recognition Words Written Test "P1" for Moroccan Children Aged 7.5 - 11.5 Years. Psychology, 9, 1397-1411. https://doi.org/10.4236/psych.2018.96085

Grégoire, J., \& Laveault, D. (2014). Introduction aux théories de tests en psychologie et en 
sciences de l'éducation (3e Édition).

Jacquier-Roux, M., Valdois, S., \& Zorman, M. (2002). Odédys: outil de dépistage des dyslexies. (L. Cogni-Sciences, Ed.). Grenoble.

Kapoula, Z., Bucci, M. P., Jurion, F., Ayoun, J., \& Afkhami, F. B.-G. D. (2006). Evidence for Frequent Divergence Impairment in French Dyslexic Children: Deficit of Convergence Relaxation or of Divergence per se? Graefe's Archive for Clinical and Experimental Ophthalmology, 245, 931-936. https://doi.org/10.1007/s00417-006-0490-4

Martin, F., \& Lovegrove, W. (1984). The Effects of Field Size and Luminance on Contrast Sensitivity Differences between Specifically Reading Disabled and Normal Children. Neuropsychologia, 22, 73-77. https://doi.org/10.1016/0028-3932(84)90009-5

Page, W. K., King, W. M., Merigan, W., \& Maunsell, J. (1994). Magnocellular or Parvocellular Lesions in the Lateral Geniculate Nucleus of Monkeys Cause Minor Deficits of Smooth Pursuit Eye Movements. Vision Research, 34, 223-239. https://doi.org/10.1016/0042-6989(94)90335-2

Stein, J., \& Fowler, S. (1985). Effect of Monocular Occlusion on Visuomotor Perception and Reading in Dyslexic Children. The Lancet, 326, 69-73.

https://doi.org/10.1016/S0140-6736(85)90179-5

Tiadi, A., Seassau, M., Bui-Quoc, E., Gerard, C.-L., \& Bucci, M. P. (2014). Vertical Saccades in Dyslexic Children. Research in Developmental Disabilities, 35, 3175-3181. https://doi.org/10.1016/j.ridd.2014.07.057

Tiadi, B. K. G. (2016). Mouvements oculaires chez l'enfant dyslexique. Paris-Saclay à l'université Paris-sud.

Vital-Durand, F. (1985). Trois canaux paralleles transmettent l'information visuelle a partir de la retine. Arguments anatomiques et physiologiques. Revue d'Electroencéphalographie et de Neurophysiologie Clinique, 15, 217-223.

https://doi.org/10.1016/S0370-4475(85)80002-2 